\title{
Insurance Policies for Clinical Trials in the United States and in some European Countries
}

\author{
Sabina Gainotti* and Carlo Petrini ${ }^{2}$ \\ ${ }^{1}$ Department of Cell Biology \& Neurosciences Istituto Superiore di Sanita', Viale Regina Elena 29900161 Roma, Italy \\ ${ }^{2}$ Bioethics Unit, Office of the President, IstitutoSuperiore di Sanità, v.le Regina Elena 299, 00161, Rome, Italy
}

\begin{abstract}
In clinical research there are important moral arguments supporting the need to offer a compensation to the injured research participants. Beneficence justifies compensation at least for the expenses of "reparative" health care, while justice requires that the risks of research do not fall exclusively on the research participants. Although the ethical arguments for compensating injured participants are generally acknowledged, the practical details are complicated particularly the determination of the extent and duration of coverage and the assignment of responsibility for paying compensation.

In this paper we analyze how several national legislations, in the United States and Europe deal with the following problems: the voluntary or compulsory requirement to draw up an insurance for the research participants; the kind of compensable injuries including death, serious harm, pain, suffering and economic losses; the compensability of harms which are inevitable in a trial and of health problems which can depend on a subject's noncompliance or on the natural progression of the subject's disease; the importance of the informed consent document and the details to be given to the research participants; the rules for compensation in phase 1 and phase 2 trials and in phase 3 and phase 4 trials, or the distinction among trials involving different levels of risk; the possibility to provide a no-fault compensation to the injured research participants when negligence cannot be established; the rules on insurance and compensation in public and private research; the actors responsible to provide compensation to the injured subjects (the State, private insurances, or both); the availability of temporal indications for the compensation of research participants.
\end{abstract}

The comparative analysis highlights the strengths and weaknesses of the analyzed legislations and proposes a model for the insurance and compensation of the injured research participants, which hopefully promotes the principles of beneficence, autonomy and justice in research.

Keywords: Compensation and redress; Research ethics; Research subjects; Human experimentation; Clinical trials; United states; Europe

Insurance issues are usually not considered as a priority in research ethics. In clinical research however there are two important moral arguments which support the need to offer compensation to the injured research participant.

Beneficence and simple humanitarism, which focus on the health care needs of the injured research participant justifies compensation at least for the expenses of "reparative" health care.

But there is another argument in favor of compensation which recalls the principle of justice. Research participants engage in experimentations which will hopefully provide useful results for future patients and need not to be harmed as a consequence. Thus, the availability of a compensation for every research participant testifies reciprocity on the part of society, to compensate participants for the risks they are undertaking.

This concept was well expressed by James Childress in 1976:

"The moral principle of fairness creates a societal obligation to this participant, who can claim as his right not merely consideration of damages but compensation at least for major injuries. This obligation is based on the relationship between the parties, not on the fact that society through biomedical research wrongfully injured the participant it reflects the moral principle of fairness" [1].

Although the ethical arguments for compensating injured participants are generally acknowledged, the practical details are complicated - particularly the determination of the extent and duration of coverage and the assignment of responsibility for paying compensation.
Preliminary distinctions should be made on the kind of compensation that the research participant is entitled to and the kind of research he/she is participating in, with the related risks.

Compensation may comprehend medical care for the long or medium term physical injuries, pain and suffering, or a sum of money to compensate psychological and social harms and economical losses. The first kind of compensation is quite common in countries with an advanced welfare system. Policies are less homogeneous as regarding other kinds of compensation.

Compensation may depend on the kind of trial the subjects are participating in. These can be early phase trials (phase 1 and phase 2) or trials with already tested products (phase 3 and phase 4).

Usually in phase 1 trials the subject-participant is a healthy volunteer. Healthy volunteers contribute to the development of scientific knowledge without gaining any advantage for their health. Hence, according to some authors, protective interventions should only be adopted to compensate healthy volunteers [2].

*Corresponding author: Sabina Gainotti, Department of Cell Biology \& Neurosciences Istituto Superiore di Sanita', Viale Regina Elena 29900161 Roma, Italy, Tel: +39-06 4990 4245; Fax +39-06 4990 4248; E-mail: sabina.gainotti@iss.it

Received July 29, 2010; Accepted August 19, 2010; Published August 19, 2010

Citation: Gainotti S, Petrini C (2010) Insurance Policies for Clinical Trials in the United States and in some European Countries. J Clinic Res Bioeth 1:101 doi:10.4172/2155-9627.1000101

Copyright: (c) 2010 Gainotti S. This is an open-access article distributed unde the terms of the Creative Commons Attribution License, which permits unrestricted use, distribution, and reproduction in any medium, provided the original author and source are credited. 
According to other authors also patients (non healthy volunteers) participating to early phase trials should receive a compensation if they are harmed as a result of participation.

The patients involved in early phase trials may not benefit from participation, due to the inherent uncertainty of research. Moreover, patients participating in research may be motivated by a desire to help society and their participation will possibly contribute to scientific knowledge [3].

Patients participating in phase 3 and phase 4 trials do not run the same risks as patients included in early phase trials as they usually receive the same drugs that they would receive in ordinary care. Moreover, they are usually more carefully monitored as compared to patients treated in ordinary care.

Therefore, the practice to insure all patients-subjects participating to a clinical trial, independently from the level of risk of the trial is more questionable.

\section{Inadequacy of Tort Litigation as a System for Compensation in Research}

After an injury has occurred it may be difficult to ascertain its causes.

If the subject-participant is a patient, the injury may result from the natural progression of the disease. The injury may also result from a negligence of the clinician involved in administering the medicinal product, from a negligence of the pharmaceutical company in preparing the experimental drug or treatment, or from a negligence of the patient who failed to comply with the protocol's instructions. Or it may result from other causes which are attributable to the medicinal product but in respect of which negligence cannot be established [4].

It is generally accepted that participants have a right to compensation when negligence can be established. However, according to some legislation, when negligence cannot be established the injured participant may have the right to receive a "no-fault" compensation.

In much legislation the system of compensation for the injured trial participants is related to the tort litigation system. This means that a patient is entitled to claim damages through the courts if he/ she demonstrates that the injury was caused by a negligence of the actors responsible for the design and conduction of the trial.

Unluckily the tort system, particularly in the area of medical malpractice, is notorious for its shortcomings, including unpredictability, its tendency to under-compensate most negligently injured patients, its over-compensation of some, and its high transaction costs [3].

The tort system may be unjust to patients seeking compensation since access to justice is usually expensive and the adversarial process can be time-consuming and discouraging. This means that not all the injured participants will have the possibility to start or to conclude a claim.

The tort system may also appear unfair to the researcher. Fault based litigation requires plaintiffs to establish that the research was negligently designed, that researchers were negligent, or that the subject didn't give informed consent. Yet research, by its nature, involves unknown risks, uncertainty and innovation [3].
The difference between clinical care and medical research is that in research an injured subject cannot easily claim that a risk was "reasonably foreseeable in the ordinary course of events", because the nature of experiment is such that

a. unforeseeable events are to be expected and

b. there is an inherent difficulty in establishing what the "ordinary course of events" actually is.

In the case of research the concept of standard of care causes particular problems as the researcher is trying by his research to establish a new standard of care.

For these reasons, according to Guest, also the term "no-fault compensation" is an unhappy title [5].

\section{A comparative analysis of existing policies}

The complexity of the issues related to the insurance and compensation of injured research participants calls for several solutions.

In this paper we will analyze the ways in which several national legislations, in Europe and in the USA have dealt with some of the following problems:

- The voluntary or compulsory requirement to draw up an insurance for the research participants;

- The kind of compensable injuries, including death, serious harm, pain, suffering and economic losses;

- The exclusion of some kind of injuries from compensation: harms which are inevitable in a particular kind of trial, health problems which can depend on a subject's noncompliance or on the natural progression of the subject's disease, etc.;

- The importance of the informed consent document and the details to be given to the research participant;

- The distinction among early phase trials (phase 1 and 2) and other trials (phase 3 and 4) or the distinction among trials involving different levels of risk;

- The possibility to provide a no-fault compensation to the injured research participant when negligence cannot be established;

- The differences among public and private research as regarding the insurance and compensation of the research participants;

- The kind of actor responsible to provide a compensation to the injured subject: public (the State); private (Insurances); or both;

- The availability of temporal indications for the compensation of injured research participants.

The comparative analysis of the existing legislations will allow us to evaluate the strengths and weaknesses of the analyzed solutions and propose an ideal model for the insurance and compensation of the injured research participants.

\section{USA}

In the United States the policy that addresses the issue of research related injury is quite limited [6]. Under the current federal regulations [7], research institutions are not required to provide compensation to the injured research subjects. Instead, Institutional Review Boards (IRBs) are required to ensure that in research involving more than minimal risk, human subjects are informed whether any 
compensation or medical treatment will be available if an injury occurs.

If no compensation or treatment are available, the consent document must so state; likewise, if medical treatment is available, the consent document must indicate who is responsible for payment [8]. Indeed, most investigators and institutions do provide medical care, but the party responsible to pay for this care varies, and in some circumstances it can even be the participant [9].

Some institutions have developed compensation programs: a study commissioned by the Department of Health and Human Services found that most research institutions do not have policies that provide free care or compensation to injured participants. The authors of the study reviewed 129 policies at 102 academic medical centers and found that there was "no institution or sponsor offering to compensate for lost wages or pain and suffering," that 66 policies $(51.2 \%)$ provided no free care to the injured subjects, that 21 policies $(16.3 \%)$ provided free care or treatment, and health insurance served as the primary vehicle for compensation of such injuries in the United States. [10].

Some institutions are usually cited as good examples to follow in the literature on medical injuries. Among these are the Department of Veterans Affairs and the University of Washington.

Department of veterans affairs: Since 1998, the Department of Veterans Affairs (VA) has had a program for providing treatment for research related injury if the project had previously been approved by a VA research and development committee and was conducted under the supervision of VA employees. Required care is generally provided in VA facility, although there are exceptions for emergency care and for specialized care that is either not available at that facility or is not economical for the VA facility to provide. Subject noncompliance excludes one from eligibility for care, as does participation conducted for the VA under contract with non-VA individuals or institutions [6, 9].

University of Washington compensation plan for adverse effects to human subjects: The University of Washington (UW) plan has been in existence since 1972. Since 1979 it has been a self-funded no-fault plan which covers research related adverse effects. For a claim to go forward, release from tort action is required. Medical expenses are paid up to $\$ 10.000$ and as applicable, other expenses, including economic losses, may be covered. Provision of needed healthcare at UW facilities is preferred and is provided without charge, preserving the relationship between the investigator and the research participant. Adverse events that are excluded are those resulting from the participant's underlying disease or from the participant's noncompliance with study procedures [11].

In the American literature on compensation programs for research injuries mention is often made of the National Vaccine Injury Compensation Program (NVICP).

National vaccine injury compensation program (NVICP): The NVICP was developed in the 1970's as a result of a litigation crisis that threatened the manufacture and supply of vaccines in the United States [6]. Today, this no-fault compensation program is funded by 75 percent surtax on each vaccine.

NVICP is thus a federal no-fault compensation program that covers medical costs, attorney fees, lost wages, and claims for pain and suffering. Awards typically consist of an initial lump sum plus a lifetime annuity. Since the inception of the program, slightly less than half of claims have been deemed compensable.
According to Beh, part of the success of the NVICP is based on the predictability of the risks involved.

Research injury on the other hand by its very nature is unpredictable. Moreover, because the type of research varies so much, even if better data about past injuries existed, it would still be challenging to predict future rates of injuries [3]. However, the potential risks of injury posed by a particular protocol can be approximated in advance and IRBs are usually engaged in the task.

Actually, in the United States the failure to address the issue of compensation not only exposes subjects of research to a possible wrong, it exposes the entire research enterprise to the public recriminations that could follow document serious uncompensated injuries to subjects.

On 1982, the President's Commission for the Study of Ethical Problems in Medicine and Biomedical and Behavioral Research proposed a study, to be conducted with federal funding at a small number of institutions, to define and to evaluate compensation of injured subjects on a no-fault basis [13]. This proposal was never implemented, although it was endorsed in 1995 by the Advisory Committee on Human Radiation Experiments and in 2001 by the National Bioethics Advisory Commission (NBAC), just prior to its decommission [14].

Thereafter, in 2003, the Institute of Medicine issued the recommendation that "organizations conducting research should compensate any research participant who is injured as a direct result of participating in research, without regard to fault. Compensation should include at least the costs of medical care and rehabilitation, and accrediting bodies should include such compensation as a requirement of accreditation" [15].

However, at present, the United States still lacks national standards for either no-fault procedures or compensation guidelines for research-related injuries [8].

\section{Europe}

In Europe a common legal framework for the insurance of subjects participating to clinical research is set up by the EU Directive 2001/20 [16].

According to the Directive a clinical trial may be undertaken only if "provision has been made for insurance or indemnity cover the liability of the investigator and sponsor" (Article 3: Protection of clinical trial subjects. Point 2 letter f).

The Directive also requires the Research Ethics Committees (RECs), which must approve all clinical trials before their commencement, to consider in preparing their opinion:

(h) Provision for indemnity or compensation in the event of injury or death attributable to a clinical trial;

(i) Any insurance or indemnity to cover the liability of the investigator and sponsor; (Article 6: Ethics Committee. Point 2).

\section{Belgium}

In Belgium clinical trials are regulated by the "Loi relative aux expérimentations sur la personne humaine du 7 mai 2004» [17].

Insurance policies are enunciated in Chapter XVII (Responsibility and insurances) article 29, stating that "The sponsor must assume responsibility, even on a no fault basis, for the injury caused to the participant or, if death occurs, to his or her "having rights". Injury must be directly or indirectly related to the clinical experimentation". 
Before starting the trial the sponsor must contact a private insurance to cover responsibility of the sponsor and of the other actors intervening in the trial independently from their relation with the sponsor and the participants.

\section{France}

In France several articles of the Code de la Santé Publique [18] are dedicated to the insurance and compensation of injured research participants.

The French law (Article L. 1121-7) discriminates among research "with individual direct benefit" and "without individual direct benefit".

In research "without individual direct benefit", the sponsor must always pay compensation to the injured subject or to his or her "having rights", even on a no fault basis and even if the subject retreated early from the trial.

In research "with individual direct benefit" the sponsor must pay compensation to the injured subject or to his or her "having rights», even if the subject retreated early from the trial, unless the sponsor can demonstrate that that the injury was not attributable to his/her negligence or to a negligence of other actors who participated in the conduction of the trial.

To cover liability of the parties involved, the sponsor must contact a private insurance.

When the clinical trial is "with individual direct benefit" and the sponsor's responsibility is not at stake, the injured subject can be indemnified by the National Office for Indemnisation (Article L1121$10)$.

This office is publicly funded and is charged to compensate the subjects who have been injured by a medical accident or a nosocomial infection (article L. 1142-22).

When the sponsor is the State it is not obliged to draw up an insurance but it must assume the obligations which usually pertain to the insurer.

\section{Germany}

The German Law on clinical trials requires the sponsor to draw up insurance in favor of trial participants. Its scope must be reasonably commensurate with the risks involved in the clinical trial and determined on the basis of the risk assessment. According to the German law, when benefits are paid by the insurance, all claims to damages shall be extinguished [19].

\section{Italy}

In Italy, before the commencement of a trial, the sponsor must present to the ethics committee a certification of insurance written in Italian and subscribed by the insurance company. Certification must specify the length of insurance coverage after trial completion and the maximum sum payable by insurers for protocol and for person. The insurance policy is to grant "specific cover in connection with the reimbursement of damages caused to the subjects by the clinical trial activities throughout the entire duration thereof, thus covering any civil liability of investigator and sponsor of the clinical trial, without excluding any damage which may be unintentionally caused by accident e/o be attributed to negligence, imprudence or inexperience, provided that they showed themselves within the periods set forth" [20] (Article. 1).
This statement would seem to imply the possibility for the injured research participant to receive a no-fault compensation in the case of accidental injury.

However, another article of the same Decree seem to partially disconfirms this hypothesis: "Insurance shall cover death, all permanent and/or temporary impairment of health conditions, relevant financial consequential losses which are the direct consequence of the trial and which can be traced to the liability of all persons operating for the performance of the trial" [20] (Article 2).

Requests for compensation can be presented until 36 months since the completion of the trial but, in trials whose damages are expected to appear in a greater time interval, the length of insurance coverage must be extended.

In the trials including minors the length of insurance coverage must be of at least 10 years.

Also in clinical trials with gene therapies, cellular therapies and radiotherapies the length of insurance coverage will be at least of 10 years.

Insurance shall cover death, all permanent and/or temporary impairment of health conditions, relevant financial consequential losses which are the direct consequence of the trial and which can be traced to the liability of all persons operating for the performance of the trial.

When the sponsor is the State or another public subject the costs for insurance are settled within the limits of available allocations.

General Directors of the healthcare structures involved in the conduction of the trial must ensure that insurance is available. The costs for the insurance of no-profit clinical trials are comprehended in the insurance coverage foreseen for normal clinical practice or research practice of the structure, according to regional and communal indications [21].

\section{The Netherlands}

In the Netherlands a clinical trial cannot be conducted unless at the time of its commencement a contract of insurance has been closed to cover losses due to death or injury resulting from the trial.

However, if in the opinion of the committee the nature of the research is such that participation entails no inherent risk for the subject, the committee may discharge the sponsor from his obligation to close a contract of insurance [22].

If the sponsor has been discharged from the obligation to close a contract of insurance, the subject participant shall be informed of this fact in the informed consent document.

The insurance shall cover death and injury to the subject occurring or coming to light while the subject is participating in the research, as well as death and injury occurring or coming to light during the five-year period immediately following the subject's participation in the research.

The insurance need not cover injury to the subject's health which would also have occurred if the subject had not participated in the research.

Moreover, the insurance need not cover injury which is inevitable or almost inevitable, given the nature of the trial [23]. The clinical trial may be undertaken only if, at the time of its commencement, provision has been made for insurance to cover the liability of the 
investigator or the sponsor, or if there is some other adequate guarantee that their obligations with respect to their liability can be met.

Any liability on the part of the investigator for losses due to the death or injury of the subject shall be shared by the sponsor. Insofar as procedures relating to clinical trials take place at a facilitative institution, the liability shall be shared by that institution, even if the institution does not itself conduct the research.

These rules shall not apply to clinical trials sponsored by central government departments or institutions designated by the Minister. However, even in public trials injured parties shall have the same rights as they would otherwise have in relation to insurers.

\section{UK}

According to the Medicines for Human Use Regulations the local research ethics committee (REC) in preparing its opinion must consider

- Provision for indemnity or compensation in the event of injury or death attributable to the clinical trial;

- Any insurance or indemnity to cover the liability of the investigator or sponsor [24].

The National Patient Safety Agency draw up a document on Standard Operating Procedures for Research Ethics Committees which provides guidance to the RECs on the issue of "Insurance, indemnity and compensation" of research participants [25].

According to this document before confirming a favorable opinion on any research, the main REC should assure itself that the sponsor and investigators will have appropriate insurance or indemnity cover for the potential legal liability arising from the research arising from the management, design and conduct of the research.

The availability of compensation in practice arises predominantly through two sources; the so-called National Health Service (NHS) indemnity and the medical insurance associations.

NHS organizations acting as sponsors or co-sponsors of research, and Chief Investigators. Principal Investigators and other staff involved in designing or conducting research within the terms of substantive NHS employment contracts will normally have access to the NHS indemnity schemes. When conducting a clinical trial, commercial sponsors must contract private insurance or indemnity. The Department of Health has developed specific policy on NHS indemnity for handling clinical negligence claims, including those arising from research [26].

In commercially sponsored studies at a mix of NHS and nonNHS sites, investigators employed by the NHS would be covered by NHS indemnity but separate insurance or indemnity cover would be required for the sponsor and any investigator who is conducting the research at a non-NHS site, including independent practitioners recruiting private patients.

One section of the Standard Operating Procedures for Research Ethics Committees is dedicated to no fault compensation or "Compensation for harm where liability does not arise". Here it is stated that in the case of commercially sponsored CTIMPs, no fault compensation to participants should be available under the Association of British Pharmaceutical Industry (ABPI) scheme.
Such scheme applies to phase 2 and phase 3 studies [27]. Other $\mathrm{ABPI}$ guidelines provide guidance on the compensation, indemnity and insurance of phase 1 trials: "Before the start of a commercially sponsored phase 1 trial, the sponsor must agree to compensate the trial subjects for any injury that arises through their participation in the trial". [28].

According to the ABPI guidelines for phase 2 and 3 studies, "Notwithstanding the absence of legal commitment, the company should pay compensation to patient volunteers suffering bodily injury (including death)".[27]

Compensation should be paid when, on the balance of probabilities, the injury was attributable to the administration of a medicinal product under trial or any clinical intervention or procedure provided for by the protocol that would not have occurred but for the inclusion of the patient in the trial.

Compensation should only be paid for the more serious injury of an enduring and disabling character (including exacerbation of an existing condition) and not for temporary pain or discomfort or less serious or curable complaints".

Injury arising in clinical trials on marketed products (phase 4) may be compensated only if the injury is caused to a patient as a direct result of procedures undertaken for the trial.

According to Barton et al. (1995) the ABPI guidelines do not offer adequate coverage to subjects participants as they recommend members to compensate patient subjects of research for "more serious injury of an enduring and disabling character (including exacerbation of an existing condition) and not for temporary pain or discomfort or less serious or curable complaints", on a no-fault basis although "without legal commitment". Clearly, these guidelines are intended not to have legal force and it would be difficult to establish a contract in the absence of an express agreement with the patient.

For these reasons Barton et al. states that all LRECs should lobby the $\mathrm{ABPI}$ for their patient guidelines to be made identical to its healthy volunteer guidelines. In the meantime, LRECs should require that research information sheets contain clear information concerning lack of legal rights to compensation so that the issue becomes clearly part of the research subject's overall consent [29].

\section{Spain}

The Spanish law on clinical trials dedicates one article to the issue of insurance for subject's participants.

According to the Spanish law a clinical trial can only be started if insurance or another financial guarantee has been made available to cover any injury arising from the trial. However, this rule does not apply if, according to the research ethics committee, the trial's risks are equivalent or inferior to the risks arising in routine clinical practice.

The sponsor of the trial is responsible to insure responsibility of the sponsor, of the principal investigator and his/her staff, of the hospital or the healthcare structure where the trial will be conducted.

If the trial does not carry relevant risks and consequently does not require specific coverage or if, for other reasons, the insurance does not cover the trial's risks entirely, the sponsor of the study, the principal investigator and the centre where the study is being conducted have the "charitable" duty, even without fault, to pay a compensation to the injured subject for the physical injuries that he/ she has suffered and for its economic consequences. 
If the parties responsible to provide compensation consider that the injury does not derive directly from the experimental drug or from the diagnostic and therapeutic procedures adopted for the study, the burden of the proof rests upon them.

However, after one year since the trial completion, the burden of the proof rests upon the injured subject.

Compensation must be paid to the injured subject for the health impairment that he/she has suffered and its economic consequences, if such impairment does not derive from the natural progression of the subject's disease or if it is not comprised among the adverse reactions which are to be expected in the ordinary treatment of the subject's disease. The insurance must warrant a minimum amount of $€ 250.000$ for subject participant.

If compensation is a life annuity, the insurance must warrant $€$ 25.000 per year at least.

If the sponsor and the principal investigator are the same person and the clinical trial is being conducted in a public healthcare service, the service may adopt special facilities to insure the trial's risks (Table 1).

\section{Discussion}

The comparison among American and European countries national legislations highlighted some differences and similarities in policies for the insurance of research participants.
The first important difference concerns the nature of the insurance which is optional according to the US federal regulations and compulsory for all the European countries' analyzed legislations. From this point of view, European countries regulations guarantee more securities to the research participants.

National regulations do not always clearly discriminate among compensable and non compensable injuries.

The Belgian and the French law do not clearly indicate which harms can be compensated in clinical trials; the Deutsch and the Dutch law indicate death, permanent disability and "other harms"; the Spanish law indicates physical injuries and their economic consequences; the Italian law indicates death, serious harms, pain, suffering and economic losses. According to the UK law compensable harms vary according to the type of trial: in phase 1 trials "any injury" is compensable, while in phase 2 and 3 only the more serious harms are compensable "without legal commitment".

National regulations also differ as regarding the limits set to compensation.

In the United States the VA and UW programs exclude the possibility to compensate subjects for injuries due to the subjects' noncompliance.

European countries laws are less explicit in setting limits to the available compensation.

\begin{tabular}{|c|c|c|c|c|c|c|c|c|}
\hline & USA & Belgium & France & Germany & Italy & Holland & UK & Spain \\
\hline Compulsory insurance & No & Yes & Yes & Yes & Yes & Yes & Yes & Yes \\
\hline $\begin{array}{l}\text { Indemnifiable injuries: death, serious } \\
\text { harm, pain, suffering, economic losses }\end{array}$ & Variable & No & No & $\begin{array}{l}\text { Death or } \\
\text { permanent } \\
\text { disability }\end{array}$ & $\begin{array}{l}\text { Death, } \\
\text { serious harm, } \\
\text { pain, } \\
\text { suffering, } \\
\text { economic } \\
\text { losses }\end{array}$ & $\begin{array}{l}\text { Death and } \\
\text { other harms }\end{array}$ & $\begin{array}{l}\text { "any injury" in } \\
\text { phase } 1 \text { trials; } \\
\text { "serious harm" in } \\
\text { phase } 2 \text { and } 3 \\
\text { trials }\end{array}$ & $\begin{array}{l}\text { Physical } \\
\text { injuries and } \\
\text { their } \\
\text { economic } \\
\text { consequences }\end{array}$ \\
\hline $\begin{array}{l}\text { Limits to compensation (e.i.: exclusion } \\
\text { of the harms which are inevitable in } \\
\text { particular kind of trials; exclusion of the } \\
\text { health problems which can depend on } \\
\text { the natural progression of the subject's } \\
\text { disease) }\end{array}$ & Yes & No & No & No & No & Yes & Yes & Yes \\
\hline $\begin{array}{l}\text { Indication for the informed consent } \\
\text { document }\end{array}$ & Yes & No & No & No & Yes & Yes & No & No \\
\hline $\begin{array}{l}\text { Differences in compensation plans } \\
\text { according to the type of trial (phase } 1 \text {, } \\
2,3 \text { or } 4 \text { ) or to the level of risk of the } \\
\text { trial }\end{array}$ & $\begin{array}{l}\text { Not } \\
\text { stated }\end{array}$ & No & Yes & Yes & No & $\begin{array}{l}\text { Yes } \\
\text { (exemption } \\
\text { for studies } \\
\text { with } \\
\text { minimal } \\
\text { risks) }\end{array}$ & $\begin{array}{l}\text { Yes (different } \\
\text { kind of } \\
\text { compensation } \\
\text { available) }\end{array}$ & $\begin{array}{l}\text { Yes } \\
\text { (exemption for } \\
\text { studies with } \\
\text { minimal risks) }\end{array}$ \\
\hline No fault compensation available & Variable & Yes & Yes & Yes & Not clear & Not clear & $\begin{array}{l}\text { Yes, for phase } 1 \\
\text { trials, without } \\
\text { "legal } \\
\text { commitment" for } \\
\text { phase } 2 \text { and } 3 \\
\text { trials }\end{array}$ & Yes \\
\hline $\begin{array}{l}\text { Exemption from insurance or special } \\
\text { terms for public clinical trials }\end{array}$ & $\begin{array}{l}\text { Not } \\
\text { stated }\end{array}$ & $\begin{array}{l}\text { Not } \\
\text { stated }\end{array}$ & $\begin{array}{l}\text { Yes, } \\
\text { exemption }\end{array}$ & Not stated & $\begin{array}{l}\text { Yes, special } \\
\text { terms }\end{array}$ & $\begin{array}{l}\text { Yes, } \\
\text { exemption }\end{array}$ & $\begin{array}{l}\text { Yes, possible } \\
\text { exemption }\end{array}$ & $\begin{array}{l}\text { Yes, possible } \\
\text { exemption }\end{array}$ \\
\hline $\begin{array}{l}\text { Responsibility for compensation } \\
\text { (public/private) }\end{array}$ & $\begin{array}{l}\text { Private } \\
\text { and } \\
\text { public }\end{array}$ & Private & $\begin{array}{l}\text { Private } \\
\text { and public }\end{array}$ & Private & Private & $\begin{array}{l}\text { Private and } \\
\text { public }\end{array}$ & $\begin{array}{l}\text { Private and } \\
\text { public }\end{array}$ & $\begin{array}{l}\text { Private and } \\
\text { public }\end{array}$ \\
\hline Temporal indications & $\begin{array}{l}\text { Not } \\
\text { stated }\end{array}$ & No & No & No & $\begin{array}{l}\text { Yes, } 24-36 \\
\text { months after } \\
\text { the trial } \\
\text { completion } \\
10 \text { years for } \\
\text { pediatric } \\
\text { studies and } \\
\text { studies with } \\
\text { biological } \\
\text { materials }\end{array}$ & $\begin{array}{l}\text { Yes, } 5 \\
\text { years after } \\
\text { subject's } \\
\text { participation }\end{array}$ & No & No \\
\hline
\end{tabular}

Table 1: Comparison of USA and European Countries regulations on the issue of insurance and compensation of injured research participants. 
Only the Dutch, the English and the Spanish laws clearly exclude the possibility to compensate subjects for the injuries which are almost inevitable in a trial or which would normally arise as a consequence of the natural progression of the disease.

In our opinion national laws should clearly indicate the kind of injuries for which compensation is available in research, to make research participants aware on what they can expect should an injury occur.

The same information should be written in the informed consent document. At present, not all legislations give detailed indications on the kind of information on insurance that must be written in the informed consent documents. In our view the informed consent document should clearly indicate what kind of compensation is available for what kind of injury, the limits to compensation, the times required to demand and obtain a compensation and the actors responsible for financial reimbursement.

The distinction according to the kind of trial (phase 1, 2, 3 and 4 ) or according to the level of risk of the trial is treated differently in the analyzed laws.

In France the distinction according to the kind of research (with or without individual direct benefit) concerns the actor responsible for compensation, according to his or her level of responsibility (in research without individual direct benefit the sponsor is always responsible, in trials with individual direct benefit the sponsor is responsible if he/she commits negligence, otherwise compensation is a responsibility of the State).

In the UK the distinction according to the kind of research (phase $1,2,3$ and 4) concerns the "extension" of available compensation: for "any injury" in phase 1 studies and only for the more serious harms in phase 2 and phase 3 studies. Moreover, the distinction concerns the possibility to obtain a "no fault" compensation which is mandatory in phase 1 trials and not mandatory in phase 2, 3 and 4 studies.

In Spain and the Netherlands clinical trials with a low level of risk can be exempted from the duty to draw up insurance. On the contrary, the Belgian and the Italian laws do not make special distinctions according to the level of risk of the trial.

A relevant difference among the US regulations and the European countries laws concerns the possibility for the injured research participant to obtain a no fault compensation when liability do not arise.

In the United States no fault compensation is previewed by the NVICP, but it is not often applied to clinical research. On the contrary, in European countries legislations the possibility for an injured research participant to obtain a no-fault compensation is quite common.

Faulting a public health insurance in the United States the lacking of no fault compensation plans for clinical trials may have negative consequences for the entire U.S. research enterprise, as it makes an injury more expensive for either the researcher or the human subject than it is in countries where public health insurance is the primary payer.

Compensating subjects for injuries may constitute a financial hardship for researchers, sponsors, or institutions in some cases and there may be situations where researchers, sponsors, or institutions do not have enough resources to compensate subjects fully or establish an effective compensation program. However, these difficulties do not undercut the moral duty to compensate subjects for injuries [9].
The possibility in European countries to provide compensation to the injured subjects at least for the medical expenses through national health services, ensure that human subjects are not bearing the medical expenses related to an injury, as these are borne by the public who also benefits from research. If a subject doesn't have to bear the financial risks related to "reparative" healthcare he/she will be more willing to participate in clinical research and the entire research enterprise will gain from this.

No fault compensation is clearly provided by the Belgian law for the injuries "directly or indirectly related to the experimentation". Also the French, the German and the Spanish laws provide the possibility of a no fault compensation for the injured research participants while the Italian and the Dutch law are less clear in this regard.

Finally, an important point of comparison of the laws concerns the distinction among public and commercial research.

Public clinical research is often finalized to the search of treatments for rare diseases, which rarely encounter the interest of the drug industry, or to the development of knowledge thought to be useful for decision making in healthcare.

For these reasons, public clinical research should be eased and promoted.

Several laws provide facilitations for public clinical research, in the form of exemptions from insurance or of other facilitations.

The Belgian and the German law do not give clear guidance on the facilities for public clinical research, at least not in the paragraphs dedicated to the insurance of clinical trials.

In Spain, France, Holland and the UK, public clinical research can be exempted from the obligation to draw up insurance. The state however has the responsibility to compensate the injured research participants.

In Italy public clinical trials are not exempted from the obligation to draw up a private insurance. However, the insurance must be comprehended in the insurance drawn up by the structure where the clinical trial is conducted for routine clinical practice. This system for the insurance of public clinical research imposes additional bureaucratic duties on the sponsor of the clinical trial and on the competent authority of the relevant healthcare structure. However, it exempts the State from the duty to organize a central system for the indenisation of injured subjects as it has been settled in other EU countries.

\section{Conclusion}

Faulting precise data on the number of requests for compensation made by the injured trial participants and the number and entity of the supplied compensation, the validity of national laws on the insurance of research participants is hardly valuable.

However, the strengths of all the analysed laws can be summed up to define a profile of the (ethically) ideal regulation for the insurance of research participants.

Such a law should respect and promote the ethical principles of beneficence, autonomy and justice in clinical research.

Beneficence: to warrant the subject participant's good, compensation should be always warranted if an injury occurs. Compensation should cover at least the expenses for "reparative" medical care and it should be offered for the injuries related to a negligence of the actors responsible for the trial's design and 
conduction (the sponsor, the principal investigator and his/her staff, the drug company, and others) as well as for the injuries which are not due to professional negligence.

No fault compensation systems are a guarantee for the research participants and should be promoted and adapted to the different context of private insurances and public security.

Autonomy: subjects should be able to freely and consciously decide to participate in a clinical trial even as regarding the more bureaucratic and apparently less relevant aspects of the trial. For this reason national laws should provide clear indications on:

- The kind of injuries which can be compensated in the trial (death, permanent invalidity, pain, suffering, economic losses, etc.)

- The limits of the available compensation (indicating the injuries which are to be expected due to the nature of the experimental drug or the subject's disease, and the injuries due to the subject's noncompliance with the trial procedures can or cannot be compensated)

- The actors responsible for compensation: private insurances, healthcare structures, the State, etc.

- The times required to make a request for compensation

- The information to be given in the informed consent document.

Apart from the law, the informed consent forms should contain a minimum set of information on the insurance schemes and on compensation plans.

\section{Justice}

Actually some of the analyzed national laws provide for different insurance programs according to the kind of clinical trial (phase 1, 2,3 or 4 ) or according to the level of risk of the clinical trial. In our view, the subjects participating in early phase trials undergo specific risks and need appropriate protective measures. These subjects should be insured and receive compensation if they are harmed as a consequence of participation.

On the contrary, subjects participating to phase 3 and phase 4 trials, run lower levels of risks and are usually better monitored as compared to patients followed in routine clinical practice. Hence, phase 3 and phase 4 trials need not to be insured and burdened by unnecessary costs and procedures. These trials are necessary to enhance our knowledge on the marketed products and must be promoted to ameliorate current clinical practice and public health.

Also, public clinical trials must be eased. When possible, public clinical trials should be exempted from the duty to be insured provided that the research participants are afforded the same level of protection than in commercial research.

\section{Acknowledgement}

This study was partly developed for the WorkPackageWP8 (Ethics andregulatory issues) of the European Advanced Translational ResearchInfrastructure in Medicine (EATRIS) project. We thank Dr. FilippoBelardelli and Dr. Ugo Visconti for their encouragement in writing thepaper.

\section{References}

1. Childress JF (1976) Compensating injured research subjects: I. The moral argument. Hastings Cent Rep 6: 21-27.

2. Marwick C (1998) Compensation for Injured Research Subjects. JAMA 279: 1854.

3. Beh $\mathrm{H}$ (2005) Compensation for research injuries. IRB 27:11-15.

4. Barton JM, Macmillan MS, Sawyer L (1995) The compensation of patients injured in clinical trials. J Med Ethics 21:166-169.
5. Guest S (1997) Compensation for subjects of medical research: the mora rights of patients and the power of research ethics committees. J Med Ethics 23: $181-185$

6. Scott LD (2003) Research-related injury: problems and solutions. J Law Med Ethics 31:419-428.

7. The United States of America. Code of Federal Regulations - Title 45: Public Welfare 46.116 - General requirements for informed consent.

8. Steinbrook R (2006) Compensation for injured research subjects. New Engl J Med 354: 1871-1873.

9. Resnik DB (2006) Compensation for research-related injuries. Ethical and legal issues. J Legal Med 27: 263-287.

10. The Lewin Group (2005) Task Order Proposal No. 2: Care/compensation for injuries in clinical research. Draft of the final report prepared for the Department of Health and Human Services Office of the Assistant Secretary for Planning and Evaluation. Falls Church, Va.

11. University of Washington. Human Subjects Division: General Information Archive http://www.washington.edu/research/hsd/policy.php

12. President's Commission for the Study of Ethical Problems in Medicine and Biomedical and Behavioral Research (1982) Compensating for research injuries: the ethical and legal implications of programs to redress injured subjects.

13. National Bioethica Advisory Commission (2001) Ethical and policy issues in research involving human participants.

14. Institute of Medicine (2003) Responsible research: a systems approach to protecting research participants. Washington, D.C.: National Academy Press.

15. European Parliament and the Council. Directive 2001/20/EC of 4 April 2001 on the approximation of the laws, regulations and administrative provisions of the Member States relating to the implementation of good clinical practice in the conduct of clinical trials on medicinal products of human use. (2002) Med Etika Bioet 9: 12-19.

16. Belgium. Moniteur Belge. Loi relative aux Expérimentations sur la Personne Humaine. 7 May 2004.

17. France. Code de la Santé Publique. http://www.legifrance.gouv.fr/affichCode. do?cidTexte=LEGITEXT000006072665\&dateTexte=20100726

18. Germany. German Medicine Act: Sixth Chapter. Protection of Human Subjects in Clinical Trials. Section 40:3.

19. Italy. Ministry of Labour, Health and Social Policies. Decree July 14, 2009 Minimum requirements for insurance policies which safeguard participants to clinical trials of medicinal products. Official Gazette no. 213 of 14.9.2009.

20. Italy. Ministry of Health. Decree December 17, 2004. Prescriptions and general conditions for the execution of clinical trials of medicines with particular reference to those finalized to the enhancement of clinical practice as part of healthcare assistance. Official Gazette no. 43 of 22.2.2005.

21. The Netherlands. Decree of 5 July 1999, regulating obligatory insurance for medical research involving human subjects.

22. The Netherlands. Medical Research (Human Subjects) Act. March 1, 2006 Division 3. Liability and insurance. Section 7. Art. 1.

23. The United Kingdom. The Medicines for Human Use (Clinical Trials) Regulations 2004 (Clinical trials of investigational medicinal products including Phase 1 trials and gene therapy research).

24. National Patient Safety Agency. National Research Ethics Service. Standard operating procedures for research ethics committees. Version 4.0 April 2009.

25. Department of Health. Research in the NHS: Indemnity and arrangements. December 2005. available at: http://www.dh.gov.uk/prod_consum_dh/groups/ dh_digitalassets/@dh/@en/documents/digitalasset/dh_4125284.pdf

26. The Association of the British Pharmaceutical Industry. Clinical Tria Compensation Guidelines. London; January 1991.Available at: http://www. abpi.org.uk/publications/pdfs/Clinical-Trial-Compensation-GLs.pdf

27. The Association of the British Pharmaceutical Industry. Guidelines for Phase 1 Clinical Trials. London; 2007. Available at: http://www.abpi.org.uk/publications/ pdfs/phase1_guidelines.pdf

28. Barton JM, Macmillan MS, Sawyer L. The compensation of patients injured in clinical trials. J Med Ethics 1995.21:166-9.

29. Spain. Ministerio de Sanidad y Consumo. 2316 Real Decreto 223/2004, de 6 febrero, por el que se regulan los ensayos clinicos con medicamentos. Artículo 8. Del seguro u otra garantía financiera de los sujetos del ensayo. 